\title{
The Slotted Tube Overlay Geotextile in Tailing Pond Radial Seepage Test Model and Analysis of the Permeation Characteristics
}

\author{
Chun-bo Yang, ${ }^{1}$ Yuan Wang, ${ }^{2,3}$ Lin-bing Wang, ${ }^{1}$ Jing-qi Huang $\mathbb{D}^{2}{ }^{2}$ Qing-wen $\mathrm{Li}^{\mathbb{D}}{ }^{2}$ \\ and Long $\mathrm{Wu}^{2}$ \\ ${ }^{1}$ National Center for Material Service Safety, University of Science and Technology Beijing, Beijing 100083, China \\ ${ }^{2}$ Civil and Resource Engineering School, University of Science and Technology Beijing, Beijing 100083, China \\ ${ }^{3}$ College of Water Conservancy and Hydropower Engineering, Hohai University, Nanjing 100124, China \\ Correspondence should be addressed to Jing-qi Huang; huangingqi11@163.com
}

Received 10 May 2021; Revised 28 August 2021; Accepted 7 October 2021; Published 21 October 2021

Academic Editor: Zetian Zhang

Copyright (c) 2021 Chun-bo Yang et al. This is an open access article distributed under the Creative Commons Attribution License, which permits unrestricted use, distribution, and reproduction in any medium, provided the original work is properly cited.

\begin{abstract}
Slotted tube drainage system plays an important role in reducing the wetting line of tailing dam. In the past studies, the permeability coefficient of geotextile was measured separately based on one-dimensional test, and the permeability characteristics of the whole system of the slotted tube overlay geotextile were rarely studied. Firstly, a set of radial flow test equipment for infiltration system of the slotted tube overlay geotextile is developed in this study. Then, with the aid of the test device, a two-dimensional radial flow test is conducted to investigate the drainage system of the slotted tube overlay geotextile before and after blocking by tailing sands, with considering different water head difference and the number of geotextile layers. By the two-dimensional radial flow test, it can be concluded that (1) the permeability coefficients of the slotted tube overlay geotextile before and after blocking all have a slight upward trend with the increase of water head difference; (2) with increasing the number of geotextile layers, the permeability coefficients before and after blocking increase first and then decrease, which approaching its minimum value at about two layers; (3) under the seepage pressure, some particles might attach to or stay in geotextile. Therefore, the permeability coefficient of the slotted tube overlay geotextile after blocking is significantly smaller than that before blocking. This study offers the insight to the further research on the permeation characteristics of the slotted tube overlay geotextile system.
\end{abstract}

\section{Introduction}

As a place for storing tailing sand, tailing ponds are widely distributed in various regions of China and play an important role in mine production, which are mainly formed by damming valley mouths or paddocks [1]. There are more than 8,000 tailing ponds in China, most of which are in high-risk state. According to statistics, about $1 / 4$ of the tailing dam failure accidents is caused by the high position of the infiltration line and the failure of seepage control [2]. Therefore, it is of great engineering significance to conduct research on the permeation characteristics of the drainage system in the tailing pond.
Many of the existing tailing ponds in China mostly use multiple-layer geotextiles as drainage measures. One or more layers of geotextile are laid on the initial dam and play the role of drainage and filtration [3-6]. As an important drainage material in engineering, geotextile has been studied extensively by many scholars. Hu [7] studied the vertical permeability characteristics of geotextiles without load and obtained the uncertainty of the permeability coefficient of geotextile. Wang et al. [8] studied the variation of vertical permeability coefficient of filament needle-punched geotextiles with pressure and pore size. In recent years, with the improvement of the beneficiation technology, the particles of the tailing sand have become smaller and smaller, most 
of which are fine powder group, clay particle group, and colloidal particle group [9]. Therefore, the pores between the tailing sand particles are pretty small, and the permeability of the fine-grained tailing medium is weak, which leads to the high infiltration line of the tailing dam and the difficulty of dam drainage. At present, the slotted tube drainage system, as a new type of tailing dam drainage technology, has a wide range of applications in fine-grained tailing dams, which can effectively reduce the infiltration line of tailing dams. The basic structure of the slotted tube is illustrated in Figure 1. Several rectangular slots are evenly cut along the axial direction of the PE plastic tube. Round holes with a diameter of $8 \mathrm{~mm}$ are opened in the slot. The plastic tube is wrapped with geotextile or white steel mesh, which plays the dual role of drainage and filtration.

At present, many scholars have conducted lots of researches on the drainage mechanism of the slotted tube overlay white steel mesh. Jin et al. $[10,11]$ carried out the study on the drainage mechanism of slotted tube overlay white steel mesh for the fine-grained tailing dam, including the calculation method and its filter radius of the slotted tube. Peng and Jiang [12] also conducted the analysis on the seepage theory of the slotted tube overlay white steel mesh. Based on a one-dimensional indoor test equipment, Zhai et al. [13] investigated the drainage properties of slotted tube overlay white steel mesh embedded in clay soil. Comparing with the white steel mesh, the slotted tube overlay geotextile is more suitable for ultrafine tailing dams [14, 15]. However, there is relatively little research on the permeability characteristics of the slotted tube overlay geotextile. Moreover, most previous researches on the slotted tube were based on the one-dimensional test, which cannot effectively present the permeation characteristic of the slotted tube.

This study is aimed at studying the permeation characteristics of slotted tubes overlay geotextile used in tailing pond. Firstly, a two-dimensional radial flow test equipment is developed. Then, based on the new test device, the twodimensional radial flow test of the drainage system of the slotted tube overlay geotextile is carried out. Finally, the permeability characteristics of the drainage system of the slotted tube overlay geotextile are analyzed, as well as the influence of water head difference and the number of geotextile layers and tailing sand on the permeability coefficient.

\section{Radial Flow Test}

\subsection{Test Equipment and Principle}

2.1.1. Test Equipment. The two-dimensional radial flow test equipment developed in this study is shown in Figure 2. The main body of the test device includes a stainless-steel outer barrel, a slotted tube, and an overflow tube. At the center of the bottom, the outer barrel, and the slotted tube, a round hole with the diameter of $20 \mathrm{~mm}$ is cut. An overflow tube passes through the slotted tube and the round hole at the bottom of the outer barrel. The outer barrel, the slotted tube, and the overflow tube are connected by bolts to form a completely radial flow system. There are seven overflow on the lateral side of the outer barrel, which are used to con-

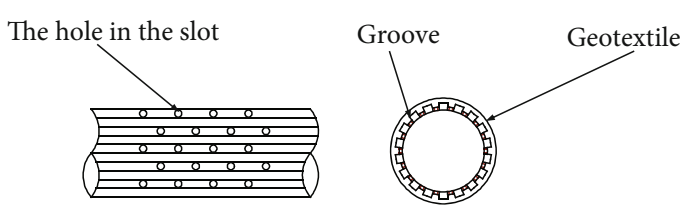

FIgURE 1: The slotted tube construction.

trol the difference between the internal and external water heads.

2.1.2. Test Principle. This test device can form a stable water head difference between the inside and outside of the slotted tube. Because of the water head difference is very small, the water flow can be regarded as a laminar flow state, which follows Darcy's law. Therefore, the whole device permeability coefficient $K[16]$ can be derived as

$$
K=\frac{Q}{2 \pi L \Delta h} \ln \frac{r_{e}}{r_{w}}
$$

where $Q$ is the volume of water flowing out of the overflow tube per unit time; $r_{e}$ is the outer barrel radius; $r_{w}$ is the slotted tube radius; $L$ is the geotextile height; and $\Delta h$ is the water head difference.

\subsection{Test Materials and Procedures}

2.2.1. Test Materials. The tailing sand used in the experiment is taken from the third tailing pond of JinChuan Concentrator. Due to the improvement of the beneficiation technology, the particle size of the tailing sand obtained is extremely small, which is measured by a laser particle size analyzer. The content of each particle of the tailing sand is listed in Table 1. The unevenness coefficient and curvature coefficient of the tailing sand of JinChuan Concentrator are about 11.19 and 1.12, respectively. The gradation curve of the tailing sand is shown in Figure 3. It can be found from this figure that the gradation is good. According to Classification Standards of Soil (ISO/TC) [17], the tailing sand is ultrafine granular soil with a natural dry bulk weight of $2.65 \mathrm{~g} / \mathrm{cm}^{3}$, a plastic limit of $15.49 \%$, a liquid limit of $24.74 \%$, and a permeability coefficient of $4.12 e^{-5} \mathrm{~cm} / \mathrm{s}$. The tailing sand is fully stirred and formulated to have a moisture content of about $35 \%$ and then left to stand for 24 hours to make it completely saturated.

The short-line needle-punched geotextile with $400 \mathrm{~g} / \mathrm{m}^{2}$ is selected in this study, which is widely used in tailing pond. The equivalent diameter is $0.08 \mathrm{~mm}$ [18]. The geotextile thickness is $0.32 \mathrm{~cm}$ (as shown in Figure 4). According to the test requirements, 6 samples of geotextiles with width and length of $20 \mathrm{~cm} \times 38 \mathrm{~cm}, 20 \mathrm{~cm} \times 76 \mathrm{~cm}, 20 \times 114 \mathrm{~cm}$, $20 \mathrm{~cm} \times 152 \mathrm{~cm}, 20 \mathrm{~cm} \times 190 \mathrm{~cm}$, and $20 \mathrm{~cm} \times 228 \mathrm{~cm}$ are cut, respectively, which are soaked in water for 24 hours before test. Inside the development device, a $80 \mathrm{~cm}$ soft ruler labeled with a scale is used to read the height of the water head.

2.2.2. Test Procedure. The two-dimensional radial flow test is conducted as following steps: 

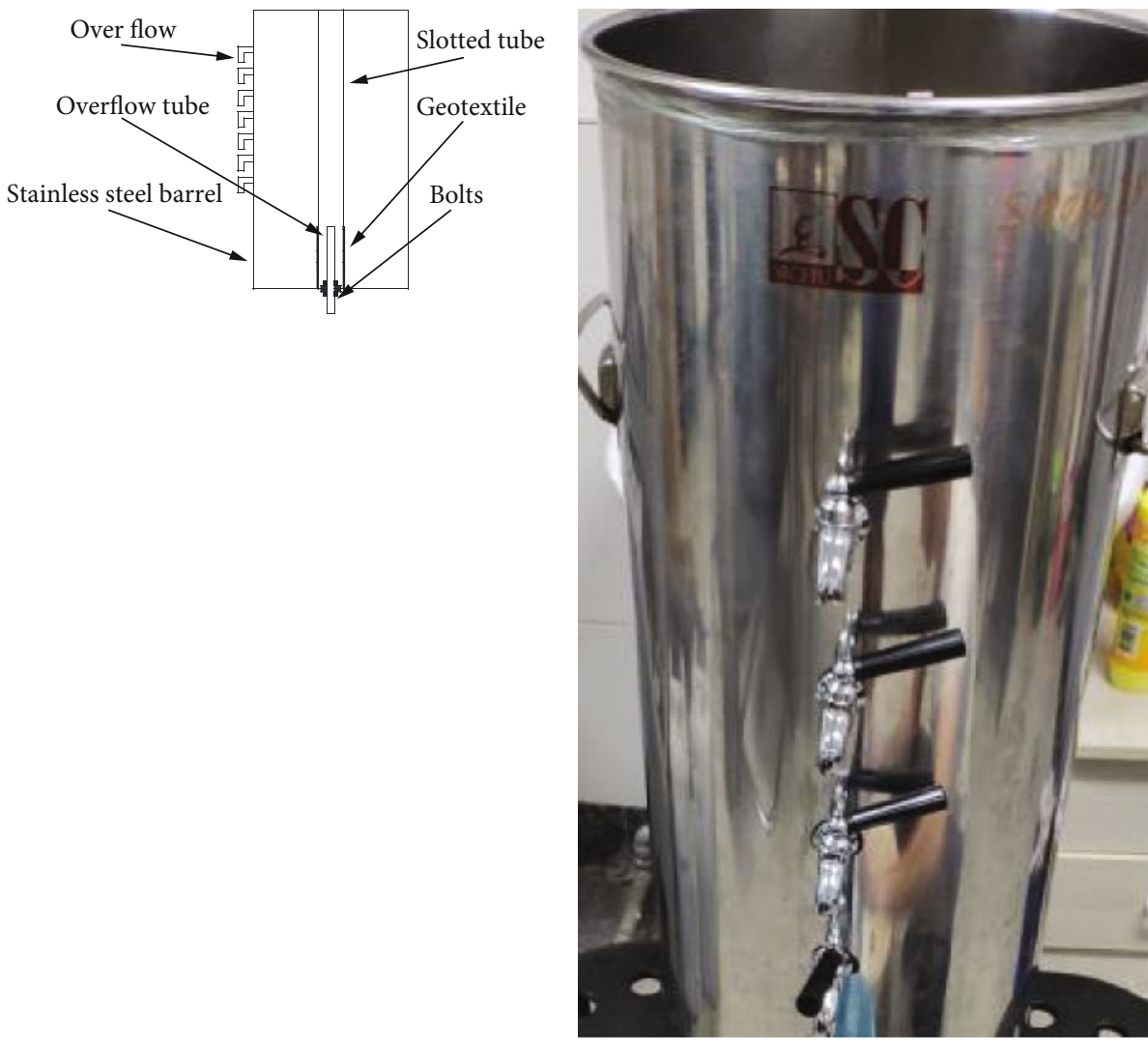

(a)

(b)

Figure 2: Two-dimensional radial flow device. (a) Equipment diagram, (b) equipment picture.

TABle 1: Particle content of tailing sand used in the experiment.

\begin{tabular}{lcccccc}
\hline Grain group & $>0.3 \mathrm{~mm}$ & $>0.2 \mathrm{~mm}$ & $>0.1 \mathrm{~mm}$ & $>0.085 \mathrm{~mm}$ & $>0.074 \mathrm{~mm}$ & $>0.035 \mathrm{~mm}$ \\
Percentage & $0.15 \%$ & $6.88 \%$ & $3.02 \%$ & $2.93 \%$ & $19.23 \%$ & $67.79 \%$ \\
\hline
\end{tabular}

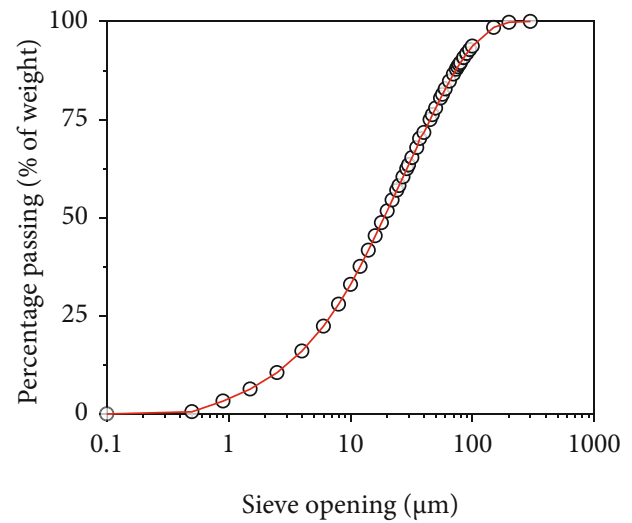

FIGURE 3: Gradation curve of the tailing sand.

Step 1. Preparing the samples of the slotted tube overlay geotextile

Wrap the slotted tube with sealed plastic, and then, install it into the outer barrel. Add water between the outside of the slotted tube and the inside of the outer barrel for half

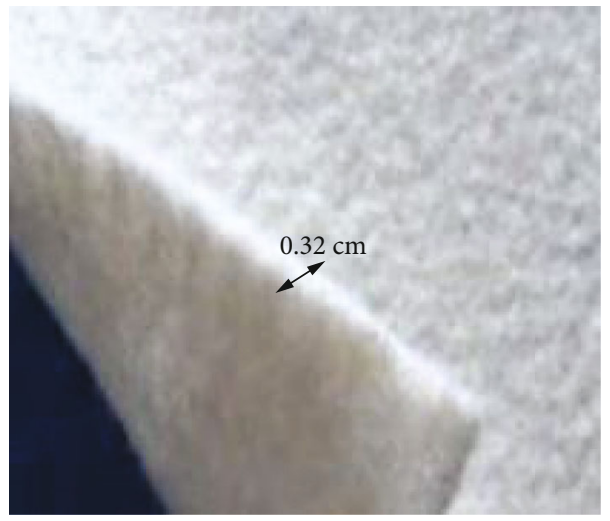

Figure 4: Geotextile picture.

an hour. If there is no water leakage, take out the sealed slotted tube and cut the sealed plastic wrapping the slotted tube with a height of $2 \mathrm{~cm}$ at a distance of $10 \mathrm{~cm}$ from the bottom. Wrap the geotextile around the opening of the sealed plastic. Then, wrap the geotextile with sealing plastic and into the 


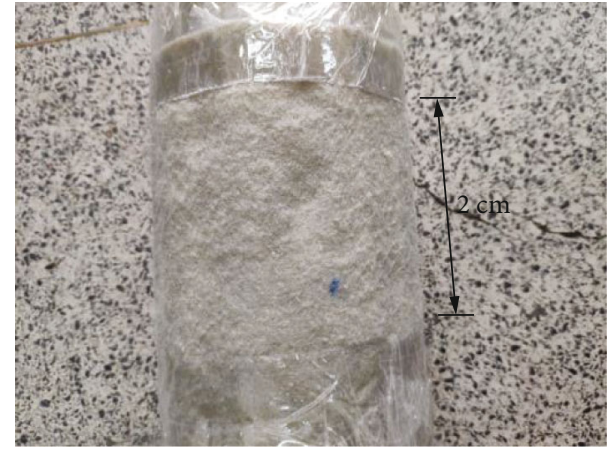

FIGURE 5: Schematic diagram of the slotted tube overlay geotextile.

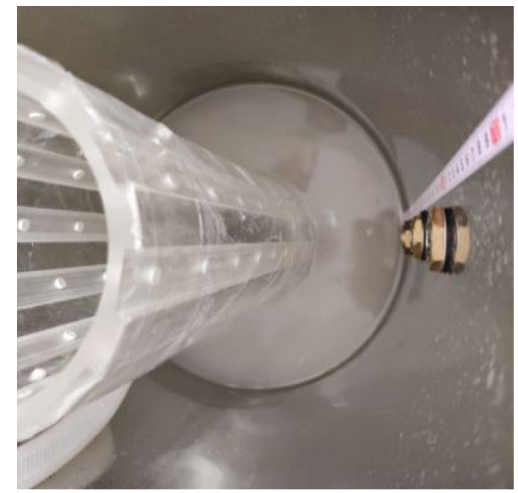

Figure 6: Schematic diagram of after water immersion.

outer barrel, then water flooding again to test the tightness. If there is no water leakage, take out the slotted tube and cut the sealed plastic wrapping the geotextile with a height of $2 \mathrm{~cm}$ at a distance of $10 \mathrm{~cm}$ from the bottom (as shown in Figure 5).

Step 2. Testing permeability coefficient of slotted tube overlay geotextile

Add water to the self-developed device until there is water flowing out of the opened overflow (as shown in Figure 6). Meanwhile, record the water output of the water outlet and time. By opening different overflow and the layer number of the geotextile, the permeability coefficient of the slotted tube overlay geotextile with different water head difference and geotextile layers can be tested and determined by Equation (1).

Step 3. Making the slotted tube overlay geotextile blockage

Put the prepared white steel mesh into the test device (as shown in Figure 7). Then, add a certain height of tailing sand between the white steel mesh and the slotted tube, as well as a certain height of clean water between the white steel mesh and the barrel. Add water to the outer barrel for 96 hours.

Step 4. Testing permeability coefficient of the slotted tube overlay geotextile under tailings after cleaning the geotextile and measuring the particle size

After step 3, remove the slotted tube and wash the geotextile properly. The cleaned tailing sand is then measured with a laser particle sizer analyzer. Then, repeat step 2 . The

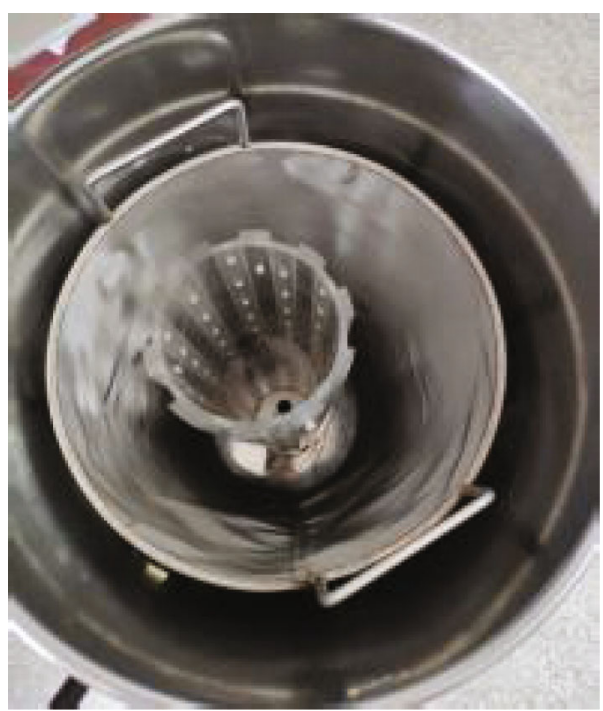

FiguRE 7: Schematic diagram before adding tailing sand.

TABle 2: Permeability coefficient $K$ of the slotted tube overlay geotextile.

\begin{tabular}{lcccccc}
\hline $\begin{array}{l}\text { Water head } \\
\text { difference }\end{array}$ & $\begin{array}{c}1 \\
\text { layer }\end{array}$ & $\begin{array}{c}2 \\
\text { layers }\end{array}$ & $\begin{array}{c}3 \\
\text { layers }\end{array}$ & $\begin{array}{c}4 \\
\text { layers }\end{array}$ & $\begin{array}{c}5 \\
\text { layers }\end{array}$ & $\begin{array}{c}6 \\
\text { layers }\end{array}$ \\
\hline $2 \mathrm{~cm}$ & 0.505 & 0.235 & 0.215 & 0.306 & 0.226 & 0.300 \\
$3 \mathrm{~cm}$ & 0.489 & 0.211 & 0.222 & 0.293 & 0.235 & 0.318 \\
$4 \mathrm{~cm}$ & 0.527 & 0.212 & 0.232 & 0.276 & 0.243 & 0.320 \\
$5 \mathrm{~cm}$ & 0.492 & 0.198 & 0.248 & 0.287 & 0.252 & 0.321 \\
$6 \mathrm{~cm}$ & 0.508 & 0.201 & 0.239 & 0.309 & 0.261 & 0.323 \\
$7 \mathrm{~cm}$ & 0.516 & 0.216 & 0.242 & 0.300 & 0.266 & 0.325 \\
\hline
\end{tabular}

permeability coefficient of the slotted tube overlay geotextile under tailings after cleaning the geotextile is studied.

\section{Test Results}

The above-mentioned test device and test steps were used to study the permeation characteristics of the slotted tube overlay geotextile and to analyze the influence of water head difference, number of geotextile layers, and tailing sand on the permeation coefficient of the slotted tube overlay geotextile.

3.1. Permeability Coefficient of the Slotted Tube Overlay Geotextile before Blocking. After step 2, the permeability coefficient $K$ of the slotted tube overlay geotextile is test and calculated by Equation (1), which are listed in Table 2 . From this table, it can be found that the permeability coefficient is affected by the water head difference and the number of geotextile layers. In the subsection, the effects of the water head difference and the number of geotextile layers are analyzed in detail.

3.1.1. Effect of Water Head Difference. The variation of the permeability coefficients of the slotted tube overlay geotextile with water head difference is shown in Figure 8 with considering different layer number. Two phenomena can be observed from Figure 8 . The first one is that the permeability 


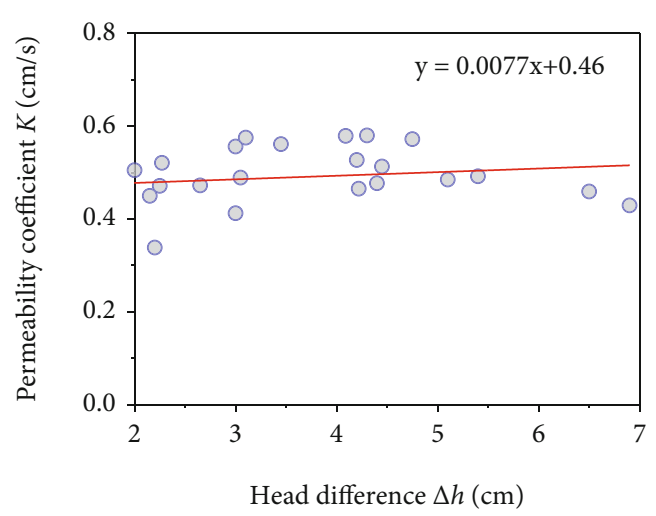

(a) 1 layer

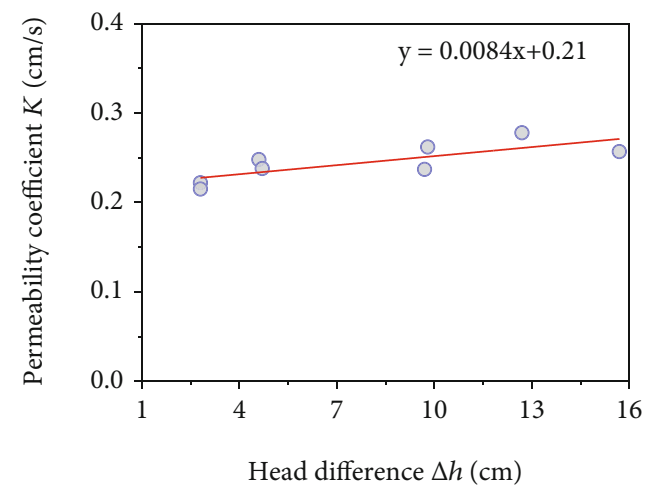

(c) 3 layers

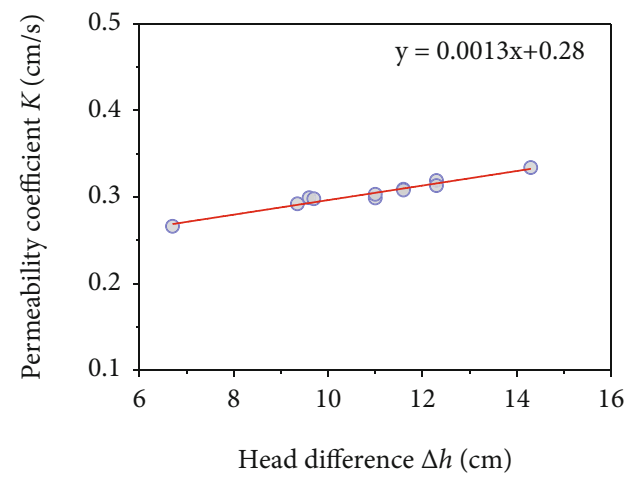

(e) 5 layers

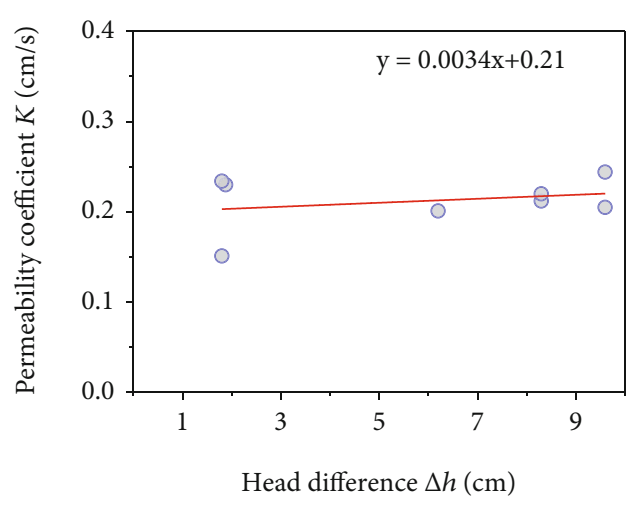

(b) 2 layers

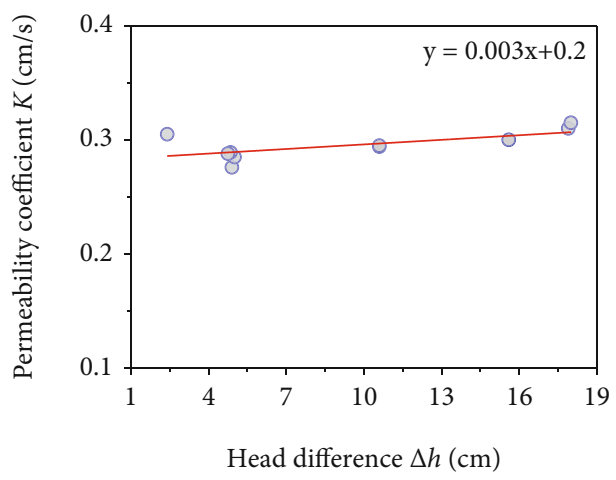

(d) 4 layers

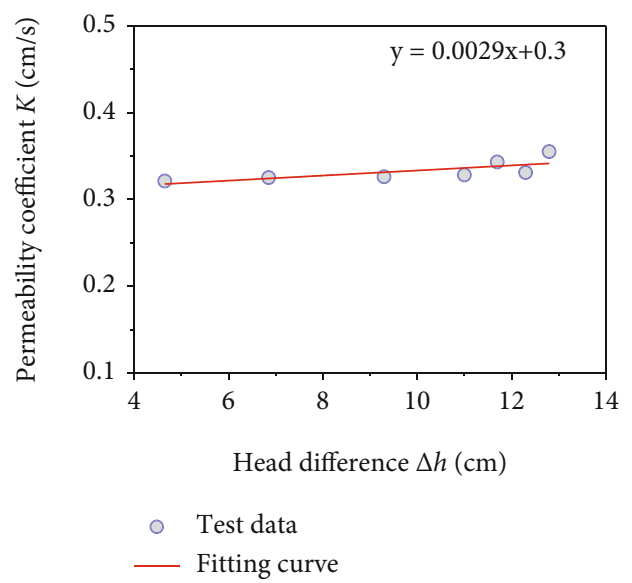

(f) 6 layers

FIGURE 8: Variation of the permeability coefficient of the slotted tube overlay geotextile with water head difference.

coefficient of the slotted tube overlay geotextile shows a certain dispersion under the same number of layers and the same water head difference condition. The reason for this phenomenon is that, as one kind of nonwoven geotextile, the short thread needle-punched geotextile consists of a number of fiber layers, which are mechanically or chemically cemented and then compacted repeatedly. Therefore, the quality of the geotextile at different locations is different, resulting in a discrete distribution of its thickness and pore space $[19,20]$ (as shown in Figures 9 and 10). As the water passing through the geotextile at different locations, due to the uneven distribution of the pores and thickness, the water output of the overflow tube in a unit time is different. Consequently, the permeability coefficient has a certain discrete nature. The second phenomenon is that the permeability coefficient of the slotted tube overlay geotextile has a slight increase with increasing the water head difference. The reason for the phenomenon can be explained as follows. With increasing the water head difference, the water flow rate increases, which brings larger impact on the geotextile. Under the action of large impact, grooves appear in the direction of the geotextile thickness, as shown in Figure 11, 


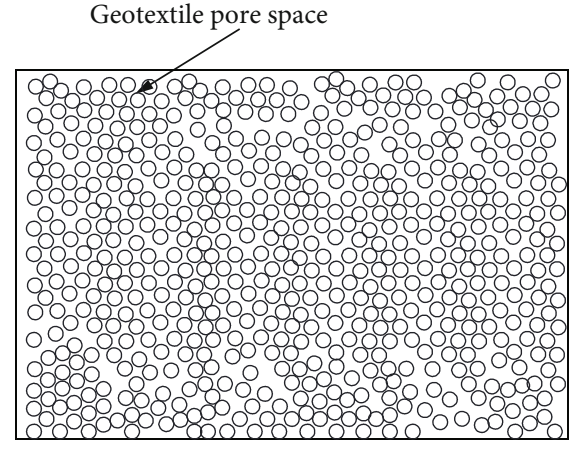

FIGURE 9: Schematic diagram of pore distribution of geotextile.

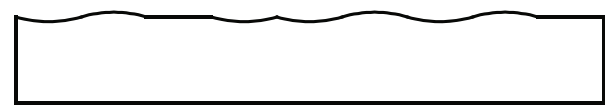

FIgURE 10: Schematic diagram of geotextile thickness.

which causes the geotextile fibers stretch and the increase of pores [21]. . Therefore, the permeability coefficient slightly increases (as shown in Figure 8).

3.1.2. Effect of Geotextile Layers. The permeability coefficient $K$ of the slotted tube overlay geotextile under different geotextile layer numbers is plotted in Figure 12, respectively, with fixing the water head difference $\Delta h$ as $2 \mathrm{~cm}, 3 \mathrm{~cm}$, $4 \mathrm{~cm}, 5 \mathrm{~cm}, 6 \mathrm{~cm}$, and $7 \mathrm{~cm}$. In general, the permeability coefficient of the geotextile in thickness direction should be maintained stable, which should be affected slightly by the number of geotextile layers. However, it can be found from Figure 12 that the number layer of geotextile has a certain influence on the permeability coefficient of the slotted tube overlay geotextile. In detail, the permeability coefficient of the slotted tube overlay geotextile decreased rapidly as the one-layer geotextile changing to be two-layer geotextile. However, as the layer number increasing continually, the permeability coefficient increases slightly. As the layer number approaching 6 , the permeability coefficient increase trend becomes steady. The main reason for the phenomenon can be explained as follows.

As mentioned above, the thickness and pore space of geotextile distribute uniformly $[19,20]$. When two layers of geotextiles freely overlap together, the pores between the two layers cannot be completely overlapped. That is to say the pores of the upper and lower layers cannot be completely matched. As the water passing through the interface between the two layers, a water layer between the two geotextile layers will be formed, as shown in Figure 13, which can slow down the water flow. Therefore, when the number of geotextile layer increases from one layer to two layers, the permeability coefficient of the slotted tube overlay geotextile reduced significantly. However, the permeability coefficient increases slightly with increasing the number of layer over two layers. This phenomenon can be attributed to the increase of the permeable area of geotextile (as illustrated in Figure 14). The geotextile fabric not only has the permeability characteristics in the vertical direction but also has certain permeability characteristics in the horizontal direc-

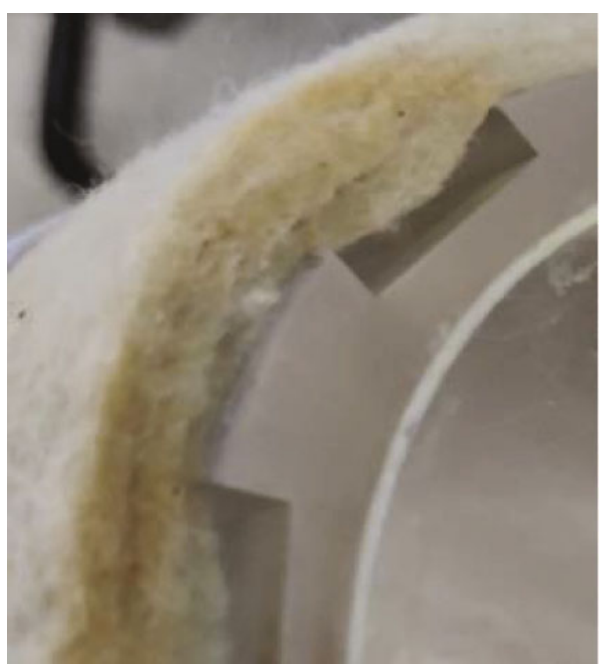

Figure 11: Grooves in the direction of the geotextile thickness.

tion [22]. So, the infiltration path is expressed not only in the horizontal direction but also in the vertical direction. Due to the slotted tube has a circular structure, the permeable area of the geotextile increases as the number of layers increases. Therefore, with increasing the number of layers, the permeability coefficient of the slotted tube overlay multilayer geotextiles is affected by two factors, i.e., water layer formed at the interface which reduces the permeability coefficient and increasing permeable area which enlarges the permeability coefficient. As the effect of water layer formed at the interface being larger than that of the increasing permeable area, the permeability coefficient deceases with increasing the layer number of the geotextile. On the contrary, the permeability coefficient increases with increasing the layer number of the geotextile. Based on the test data in this study, the permeability coefficient of the slotted tube overlay geotextile decreased rapidly first and then increase slightly to a stable values with increasing the geotextile layers. Deeper influence characteristic and mechanism of geotextile layers on the permeability coefficient of the slotted tube overlay geotextile need more effect in further studies.

\subsection{Permeability Coefficient of the Slotted Tube Overlay Geotextile after Blocking}

3.2.1. Comparing the Permeability Coefficients before and after Blocking. After step 4, the permeability coefficient $K$ of the slotted tube overlay geotextile under tailings after cleaning the geotextile is calculated, which are listed in Table 3. It can be observed from Table 3 that the permeability coefficient of the slotted tube overlay geotextile after blocking is significantly smaller than that before blocking. Under the seepage pressure, fine particles of tailing sand migrate. Some very small particles will pass through the geotextile and flow away. Since the pore size parameters of geotextile selected in the test do not match the particle gradation of tailings, some larger particles might attach on the geotextile surface (as shown in Figure 15(a)), and others stay in geotextile (as shown in Figure 15(b)). Two factors lead to cake clogging, which reduce the permeation of the geotextile 


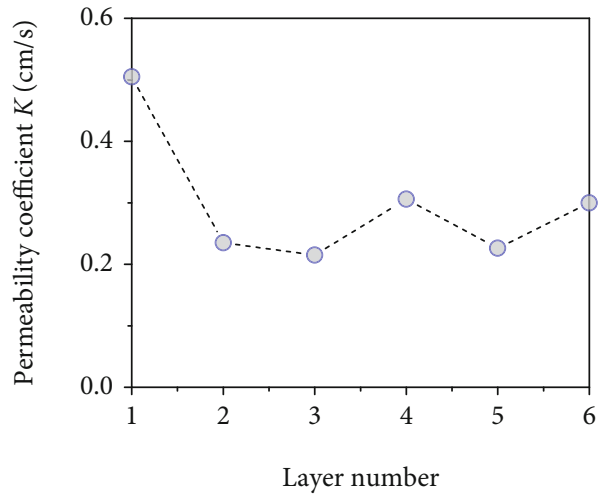

(a) $\Delta h=2 \mathrm{~cm}$

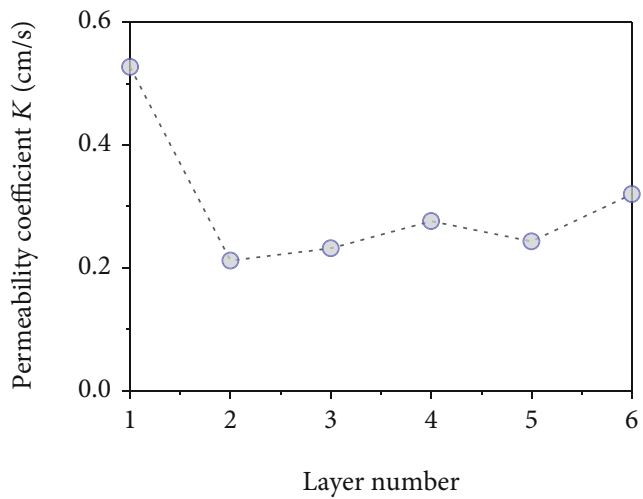

(c) $\Delta h=4 \mathrm{~cm}$

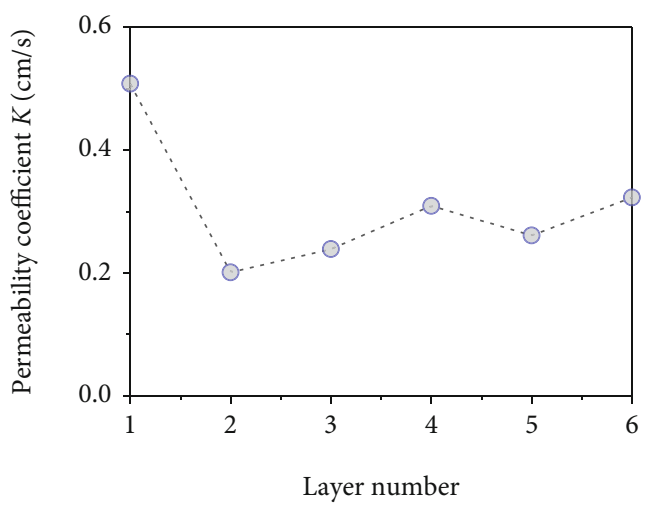

(e) $\Delta h=6 \mathrm{~cm}$

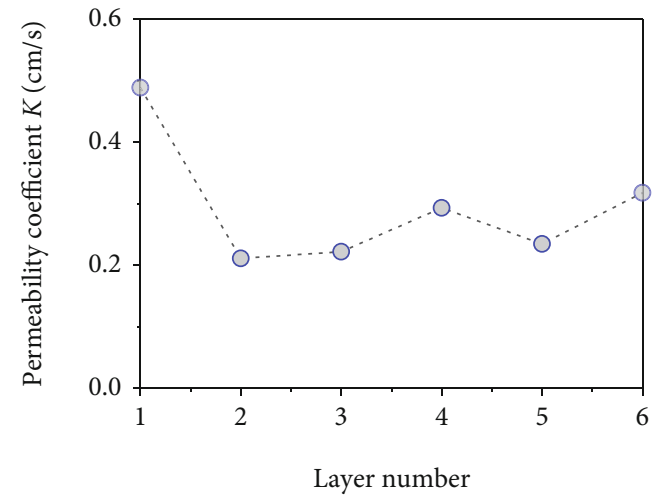

(b) $\Delta h=3 \mathrm{~cm}$

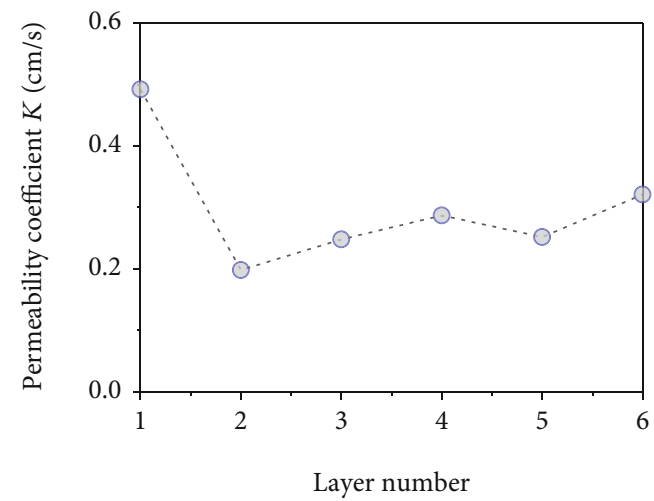

(d) $\Delta h=5 \mathrm{~cm}$

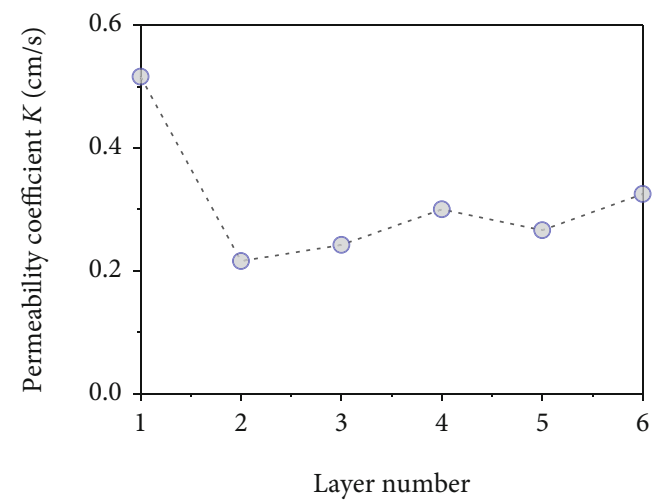

(f) $\Delta h=7 \mathrm{~cm}$

FIGURE 12: Variation of the permeability coefficient of the slotted tube overlay geotextile with geotextile layer number.

[23]. Moreover, another finding can be found from Table 3 that the water head difference and layer number of geotextile all have obvious effect on the permeability coefficient of the slotted tube overlay geotextile after blocking, which is analyzed in the following subsection.

3.2.2. Effect of Water Head Difference. The permeability coefficients of the slotted tube overlay geotextile after blocking under different water head difference are plotted in Figure 16, respectively. It can be found in Figure 16 that the permeability coefficient of the slotted tube overlay geotextile after blocking increases with increasing the water head difference. With increasing the water head difference, the water flow rate increases, which takes more tailings away (as shown in Figure 17). Under the action of the result, the penetration coefficient slightly increases (as shown in Figure 16).

3.2.3. Effect of Geotextile Layers. The permeability coefficient $K$ of the slotted tube overlay geotextile under different geotextile layers are plotted in Figure 18, respectively, with fixing the water head difference $\Delta h$ as $2 \mathrm{~cm}, 3 \mathrm{~cm}, 4 \mathrm{~cm}, 5 \mathrm{~cm}$, $6 \mathrm{~cm}$, and $7 \mathrm{~cm}$. It can be found from Figure 8 that the geotextile layers have a certain influence on the permeability coefficient of the slotted tube overlay geotextile. In detail, the permeability coefficient of the slotted tube overlay geotextile decreased rapidly as the one-layer geotextile changing to be two-layer geotextile. Conversely, when the layer 


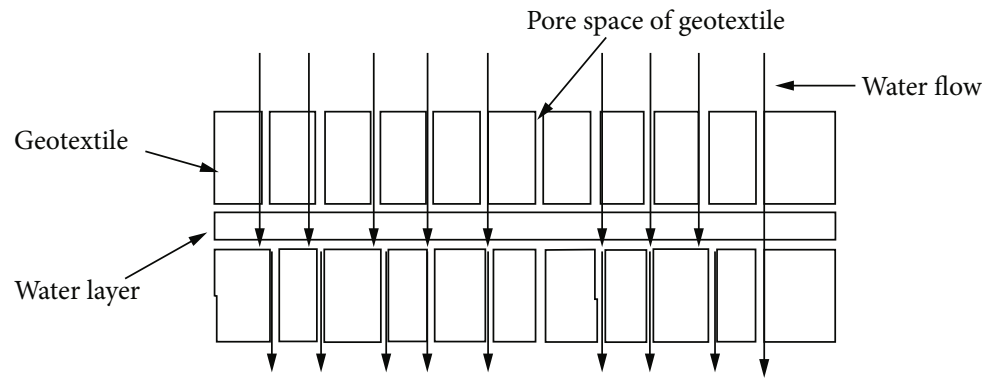

FIgURE 13: Water flow through the geotextile.

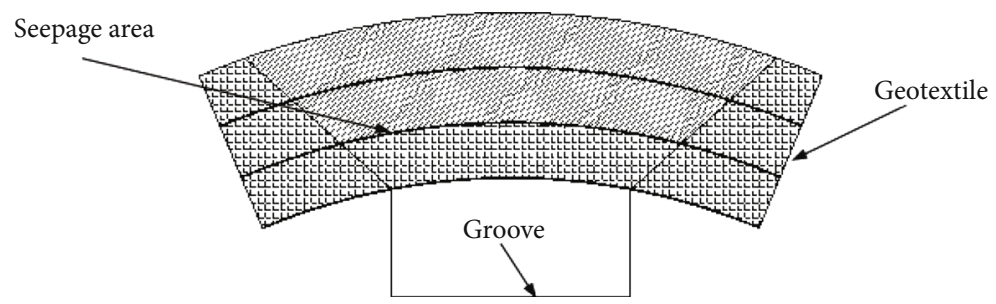

FIGURE 14: Schematic diagram of the increase of water area.

TABle 3: Permeability coefficient $K$ of the slotted tube overlay geotextile after blocking.

\begin{tabular}{lcccccc}
\hline Water head difference & 1 layer & 2 layers & 3 layers & 4 layers & 5 layers & 6 layers \\
\hline $2 \mathrm{~cm}$ & 0.058 & 0.0142 & 0.0538 & 0.0618 & 0.0751 & 0.123 \\
$3 \mathrm{~cm}$ & 0.0617 & 0.0152 & 0.0581 & 0.0705 & 0.0820 & 0.136 \\
$4 \mathrm{~cm}$ & 0.063 & 0.0155 & 0.0598 & 0.075 & 0.0839 & 0.139 \\
$5 \mathrm{~cm}$ & 0.0645 & 0.0163 & 0.0615 & 0.082 & 0.089 & 0.142 \\
$6 \mathrm{~cm}$ & 0.0683 & 0.0167 & 0.0645 & 0.100 & 0.0987 & 0.146 \\
$7 \mathrm{~cm}$ & 0.0706 & 0.0173 & 0.0693 & 0.103 & 0.153 \\
\hline
\end{tabular}

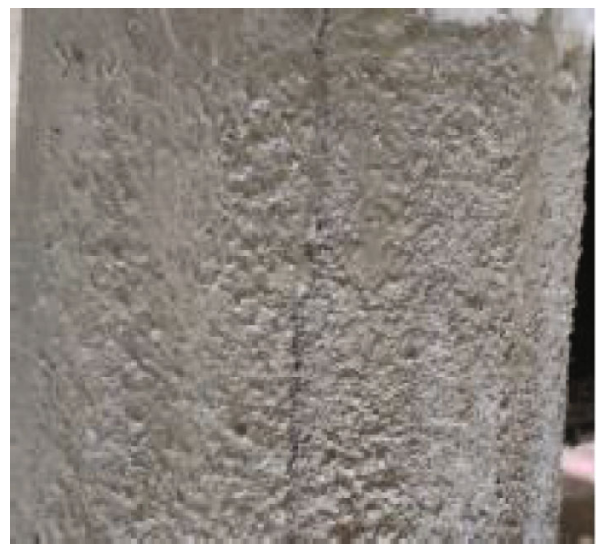

(a) Attaching on the geotextile surface

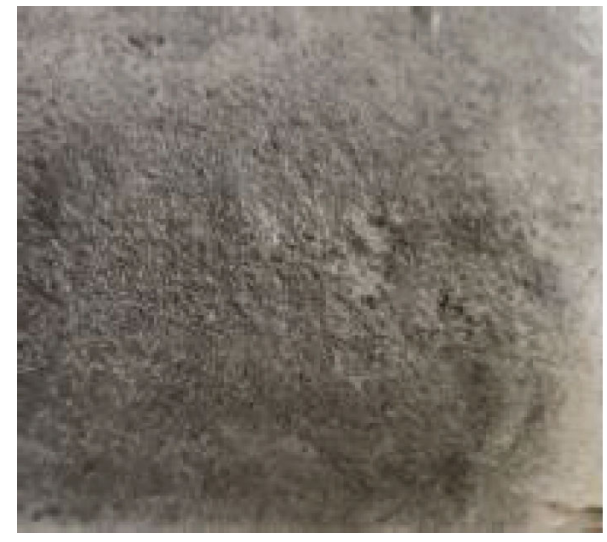

(b) Stay in the geotextile

Figure 15: Particles attaching on or staying in geotextile. 


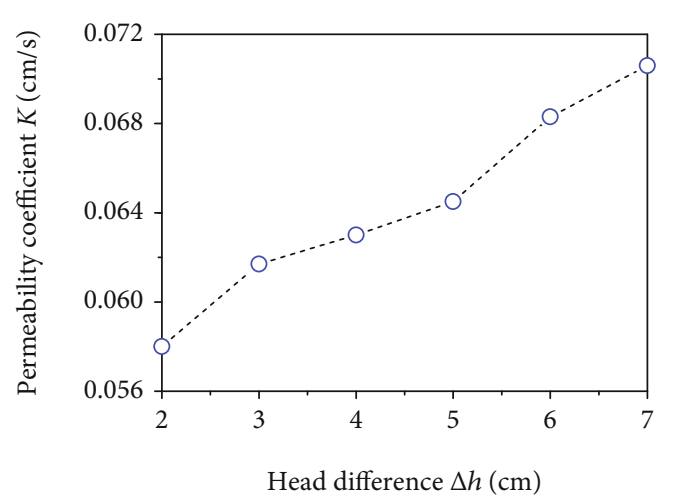

(a) 1 layer

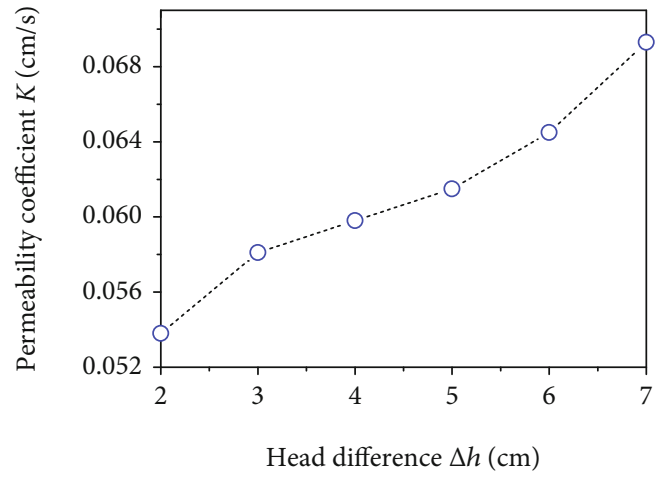

(c) 3 layers

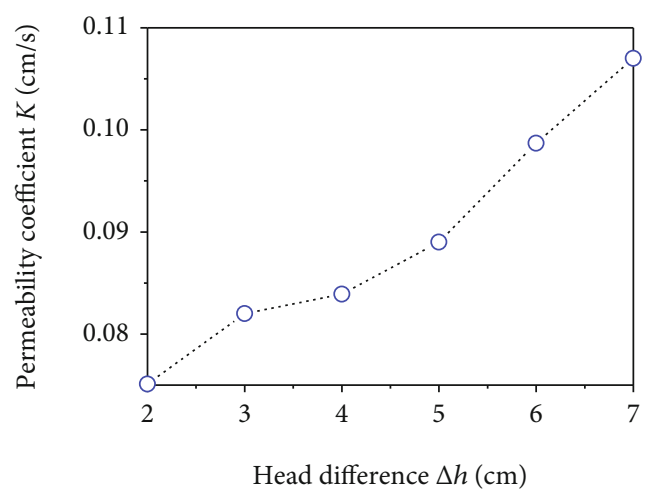

(e) 5 layers

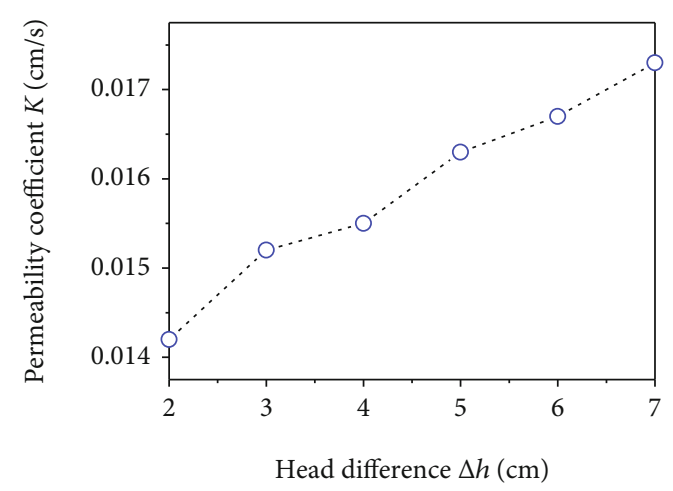

(b) 2 layers

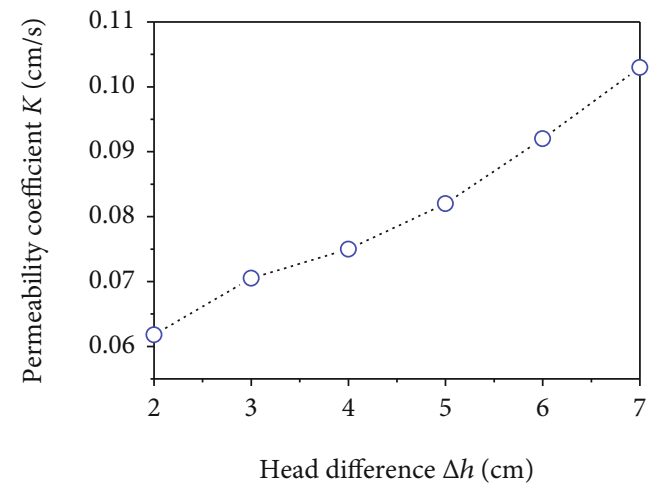

(d) 4 layers

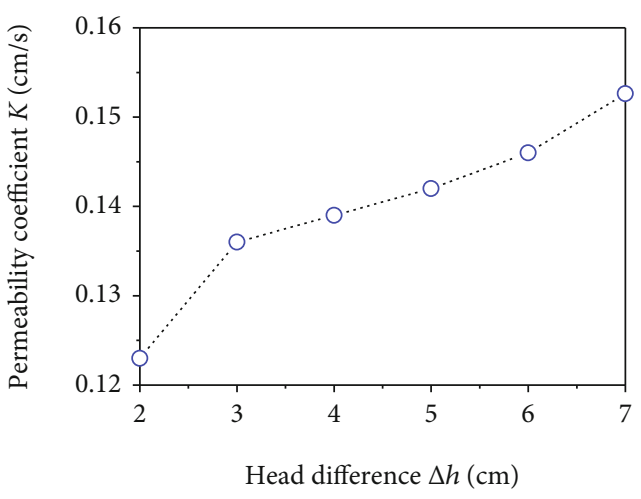

(f) 6 layers

FIGURE 16: Variation of the permeability coefficient of the slotted tube overlap geotextile layers under different head difference.

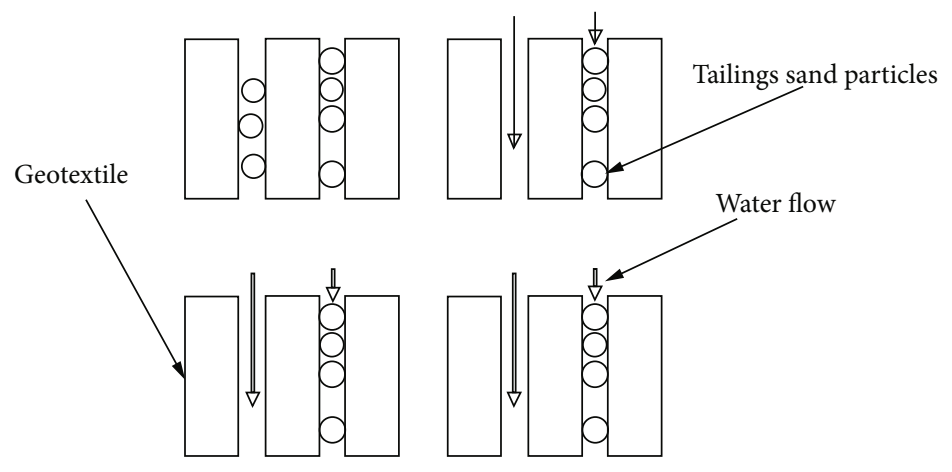

FIGURE 17: Schematic diagram of the increase of tailing sand particles in water flow. 


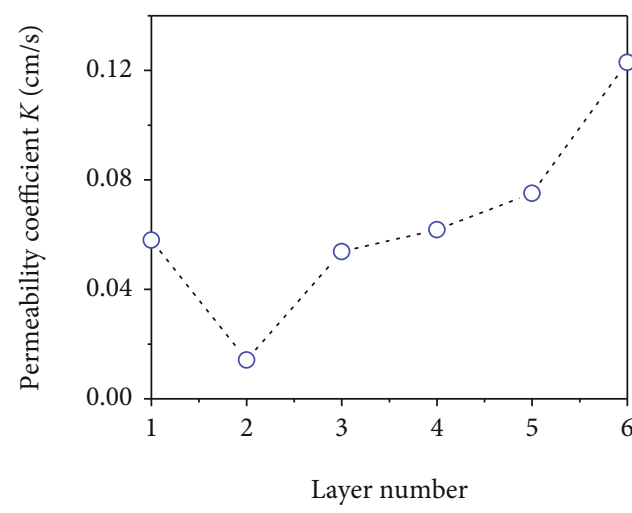

(a) $\Delta h=2 \mathrm{~cm}$

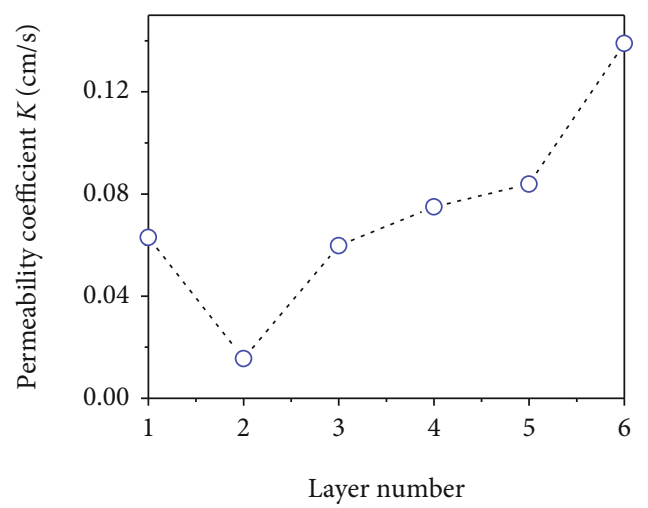

(c) $\Delta h=4 \mathrm{~cm}$

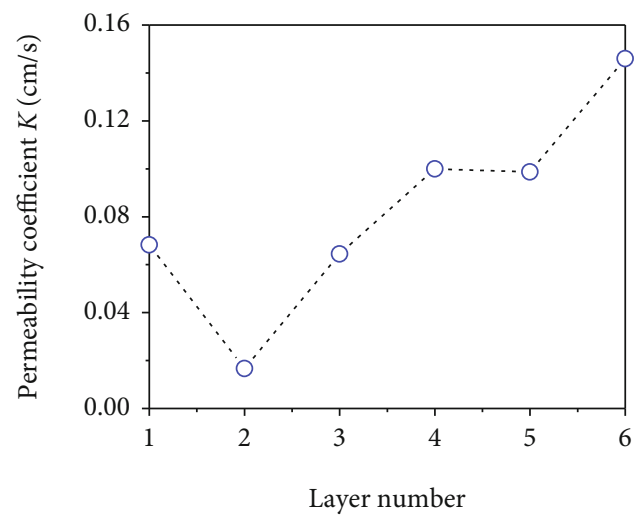

(e) $\Delta h=6 \mathrm{~cm}$

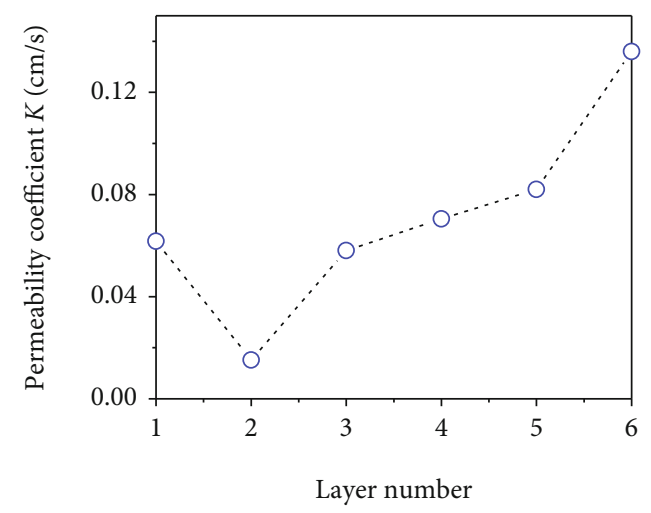

(b) $\Delta h=3 \mathrm{~cm}$

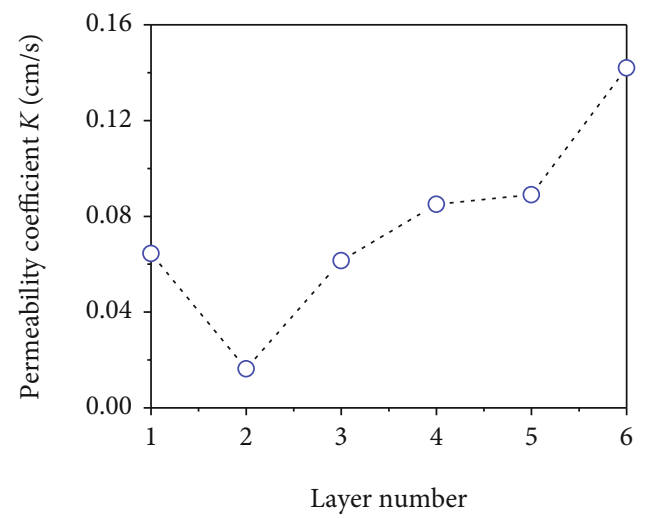

(d) $\Delta h=5 \mathrm{~cm}$

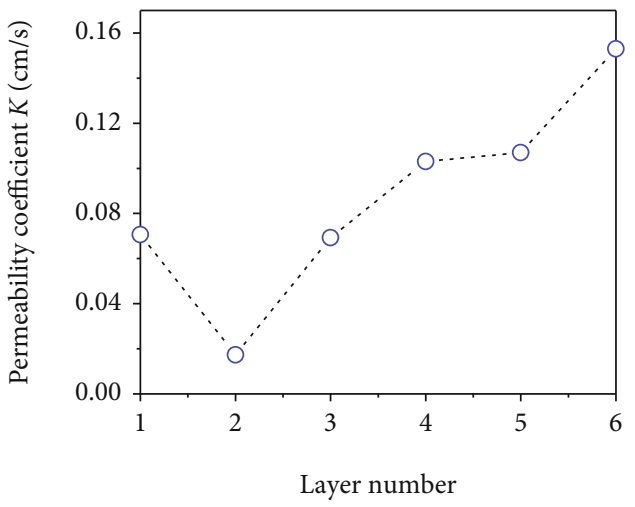

(f) $\Delta h=7 \mathrm{~cm}$

Figure 18: Variation of the permeability coefficient of the slotted tube overlay multilayer geotextile.

number continues to increase, the permeability coefficient increases rapidly. As the layer number approaching 6 , the permeability coefficient reaches the peak.

\section{Summary and Conclusions}

In this study, a two-dimensional radial flow test device is developed first. Then, with the aid of the test device, a twodimensional radial flow test is conducted to investigate the drainage system of the slotted tube overlay geotextile. Based on the test results, the permeability coefficients of the slotted tube overlay geotextile before and after blocking are ana- lyzed. Moreover, the effect of water head difference and geotextile layers on the permeability coefficient is also studied. The following conclusion can be drawn as follows:

(1) The permeability coefficient of the slotted tube overlay geotextile before blocking under the same water head difference condition has a certain discrete nature, which has a slight upward trend with the increase of water head difference. Moreover, the permeability coefficient has a downward tendency and then increase slightly with increasing the number of geotextile layers 
(2) Under the seepage pressure, some particles might attach to or stay in geotextile. Therefore, the permeability coefficient of the slotted tube overlay geotextile after blocking is significantly smaller than that before blocking

(3) The permeability coefficient of the slotted tube overlay geotextile after blocking increases with increasing the water head difference. With increasing the number of geotextile layers, the permeability coefficient increases first and then decreases, which approaching its minimum value at about two layers

\section{Data Availability}

The raw/processed data required to reproduce these findings cannot be shared at this time as the data also forms part of an ongoing study.

\section{Conflicts of Interest}

The authors declare that they have no conflicts of interest.

\section{References}

[1] A. Liu and A. Liang, "Comprehensive application of geosynthetics in solidified soil sea dike projects," Chinese Journal of Geotechnical Engineering, vol. 38, no. S1, pp. 177-180, 2016.

[2] Y. Tao, S. Wang, and D. Xu, "Experimental study of clogging defense measures for improved subsurface drainage," Transactions of the Chinese Society for Agricultural Machinery, vol. 47, no. 6, pp. 187-192, 2016.

[3] P. Wang, F. Shao, J. Liu, X. Li, Z. Hu, and S. Y. Russell, "Simulated experiment on drainage and fine sediment retention effects of geotextiles in land reclamation with Yellow River sediments," Transactions of the Chinese Society of Agricultural Engineering, vol. 31, no. 17, pp. 72-80, 2015.

[4] Z. Yan, Q. Zhong, B. Si, and S. A. Mei, "Research progress on filter design of tailing dam drainage system," Metal Mine, vol. 47, pp. 18-26, 2018.

[5] H. E. Qianqian, P. E. I. Sheng, and Y. A. N. G. Guangchao, "Performance comparison and application analysis of nonwoven geotextiles," Technical Textiles, vol. 36, no. 2, pp. 30-34 $+44,2018$.

[6] W. Wang, Z. Y. Ding, Z. Y. Guo, H. T. Zhang, and Q. Luoet, "Test research on penetrative and filtration properties of nonwoven geotextile," China Journal of Highway and Transport, vol. 3, pp. 9-12, 2004.

[7] J. Hu, "Uncertainty analysis of inspection results of vertical permeability characteristics of geotextiles without load," Building Materials and Decoration, vol. 8, pp. 42-43, 2018.

[8] X. Y. Wang, B. X. Ni, and P. Zhang, "The vertical permeability of spunbonded and needle-punched filament nonwoven geotextiles," Journal of Donghua University (Natural Science), vol. 40, no. 2, pp. 234-237, 2014.

[9] A. W. Yang, P. W. Yan, D. Du, L. Q. Lu, and J. H. Wang, "Partly improved technology of vacuum preloading in foundation treatment of soft dredger fill," Journal of Tianjin University, vol. 44, no. 6, pp. 477-483, 2011.

[10] S. Jin, H. Xu, W. Zhang, H. Yan, and Z. X. Wu, "Research on calculation method and drainage mechanism of slotted pipe in fine-grained tailings dam," Metal Mine, vol. 3, pp. 42-44 $+48,2013$.

[11] S.-L. Jin, Application Study of Slotted Orifice Pipe in FineGrained Tailings Dam Controlled Infiltration Line, North China University of Technology, 2013.

[12] H. Peng and F. Jiang, "Analysis and calculation of slot tube seepage," Gold, vol. 36, no. 8, pp. 61-64, 2015.

[13] C. Zhai, W. F. Guo, and C. Yan, "Laboratory model tests and mechanism of infiltration clogging effect of clayey soil," Chinese Journal of Geotechnical Engineering, vol. 38, no. S1, pp. 147-151, 2016.

[14] H. Jiang, G. Lei, and M. C. Yang, "Research progress of vertical infiltration characteristics of geotextiles," Advances in Science and Technology of Water Resources, vol. 34, no. 3, pp. 89-94, 2014.

[15] Q. Xia and J. Bai, "Discussion on vertical permeability performance and value method of geotextile," Shanghai Water, vol. 4, pp. 34-37, 2003.

[16] S. Deng and N. Wang, "A novel method of calculating productivity horizontal well," Natural Gas Exploration and Development, vol. 38, no. 3, pp. 59-61+12, 2015.

[17] Ministry of Water Resources of People's Republic China, Classification Standards of Soil (GBJ145-90)[S], China Planning Press, Beijing, 1991.

[18] State Textile Industry Bureau of People's Republic China, Specification for Geotextiles (GBT17638-2008)[S], China Planning Press, Beijing, 2008.

[19] W. Liu, W. Luo, Z. Jia et al., "Experimental study on geotextile envelope for subsurface drainage in Yellow River Delta," Transactions of the Chinese Society of Agricultural Engineering, vol. 29, no. 18, pp. 109-116, 2013.

[20] S. Su and W. Wu, "Determination methods for effective opening size of geotextiles," Chinese Journal of Geotechnical Engineering, vol. 38, no. S1, pp. 156-159, 2016.

[21] F. Jia and D. Zhang, "Testing of multilayer needle-punched composite nonwoven geotextile performance," Journal of Xi'an Polytechnic University, vol. 30, no. 4, pp. 411-415, 2016.

[22] T. Dai, A Study on the Horizontal Permeability Properties of Staple Fiber Needle-Punched Geotextiles, Zhongyuan University Of Technology, 2011.

[23] S. Wu, W. Zhu, F. Min, C. Zhang, and D. Wei, "Clogging mechanism and effect of cake permeability in soil-water separation using vacuum filtration," Chinese Journal of Rock Mechanics and Engineering, vol. 39, no. 8, pp. 1530-1537, 2017. 